\title{
Policies to enhance prescribing efficiency in Europe: findings and future implications
}

\section{Brian Godman 1,2,3* , William Shrank ${ }^{4}$, Morten Andersen ${ }^{5}$, Christian Berg $^{6}$, lain Bishop ${ }^{7}$, Thomas Burkhardt $^{8}$, Kristina Garuoliene ${ }^{9,10}$, Harald Herholz ${ }^{11}$, Roberta Joppi ${ }^{1,12}$, Marija Kalaba ${ }^{13}$, Ott Laius ${ }^{14}$, Julie Lonsdale ${ }^{15}$, Rickard E. Malmström ${ }^{16}$, Jaana E. Martikainen ${ }^{17}$, Vita Samaluk ${ }^{18}$, Catherine Sermet ${ }^{19}$, Ulrich Schwabe ${ }^{20}$, Inês Teixeira ${ }^{21}$, Lesley Tilson ${ }^{22}$, F. Cankat Tulunay ${ }^{23}$, Vera Vlahović-Palčevski ${ }^{24}$, Kamila Wendykowska ${ }^{25}$, Bjorn Wettermark ${ }^{3,5,26}$, Corinne Zara ${ }^{27}$ and Lars L. Gustafsson ${ }^{3}$}

1 Institute for Pharmacological Research 'Mario Negri', Milan, Italy

2 Prescribing Research Group, University of Liverpool Management School, Liverpool, UK

${ }^{3}$ Division of Clinical Pharmacology, Department of Laboratory Medicine, Karolinska Institutet, Karolinska University Hospital, Huddinge, Stockholm, Sweden

4 Division of Pharmacoepidemiology and Pharmacoeconomics, Brigham and Women's Hospital and Harvard Medical School, Boston, MA, USA

5 Centre for Pharmacoepidemiology, Karolinska Institute, Karolinska University Hospital, Solna, Stockholm, Sweden

${ }^{6}$ Division of Epidemiology, Department of Pharmacoepidemiology, Norwegian Institute of Public Health, Nydalen, Oslo, Norway

7 Information Services Healthcare Information Group, NHS National Services, Edinburgh, Scotland, UK

8 Hauptverband der Österreichischen Sozialversicherungsträger, Wien, Austria

${ }^{9}$ Department of Pathology, Forensic Medicine and Pharmacology, Faculty of Medicine, University of Vilnius, Vilnius, Lithuania

${ }^{10}$ Medicines Reimbursement Department, National Health Insurance Fund, Vilnius, Lithuania

${ }^{11}$ Kasemarzliche Vereinigung Hessen, Frankfurt am Main, Germany

12 Pharmaceutical Drug Department, Azienda Sanitaria Locale of Verona, Verona, Italy

${ }^{13}$ Republic Institute for Health Insurance, Belgrade, Serbia

${ }^{14}$ State Agency of Medicines, Tartu, Estonia

${ }^{15}$ Medicines Management, NHS North Lancashire, Lancaster, UK

${ }^{16}$ Division of Clinical Pharmacology, Department of Medicine, Karolinska Institutet, Karolinska University Hospital, Solna, Stockholm, Sweden

${ }_{17}$ Research Department, The Social Insurance Institution, Helsinki, Finland

${ }^{18}$ Health Insurance Institute, Ljubljana, Slovenia

19 Institut de Recherche et Documentation en Économie de la Santé, Paris, France

${ }^{20}$ Institute of Pharmacology, University of Heidelberg, Heidelberg, Germany

${ }^{21}$ CEFAR - Centre for Health Evaluation and Research, National Association of Pharmacies, Lisboa, Portugal

${ }^{22}$ National Centre of Pharmacoeconomics in Ireland, St James's Hospital, Dublin, Ireland

${ }^{23}$ Department of Pharmacology, Medical School of Ankara University, Sihhive, Ankara, Turkey

${ }^{24}$ Department of Clinical Pharmacology, University Hospital, Rijeka, Croatia

${ }^{25}$ HTA Consulting, Cracow, Poland

${ }^{26}$ Medical Knowledge Centre, Stockholm County Council, Stockholm, Sweden

${ }^{27}$ Barcelona Health Region, Catalan Health Service, Barcelona, Spain

\section{Edited by:}

Dominique J. Dubois, Université Libre de Bruxelles, Belgium

Reviewed by:

Oscar Richard Leeuwenkamp,

Movetis, Belgium

Iñaki Gutiérrez-ibarluzea, Nursing School, Spain

Alan Haycox, Liverpool University, UK

\section{*Correspondence.}

Brian Godman, Division of Clinical

Pharmacology, Department of

Laboratory Medicine, Karolinska

Institutet, Karolinska University

Hospital, Huddinge, SE-141 86

Stockholm, Sweden.

e-mail:brian.godman@ki.se
Introduction: European countries need to learn from each other to address unsustainable increases in pharmaceutical expenditures. Objective: To assess the influence of the many supply and demand-side initiatives introduced across Europe to enhance prescribing efficiency in ambulatory care. As a result provide future guidance to countries. Methods: Cross national retrospective observational study of utilization (DDDs - defined daily doses) and expenditure (Euros and local currency) of proton pump inhibitors (PPIs) and statins among 19 European countries and regions principally from 2001 to 2007. Demand-side measures categorized under the "4Es" - education engineering, economics, and enforcement. Results: Instigating supply side initiatives to lower the price of generics combined with demand-side measures to enhance their prescribing is important to maximize prescribing efficiency. Just addressing one component will limit potential efficiency gains. The influence of demand-side reforms appears additive, with multiple initiatives typically having a greater influence on increasing prescribing efficiency than single measures apart from potentially "enforcement." There are also appreciable differences in expenditure (€/1000 inhabitants/ year) between countries. Countries that have not introduced multiple demand side measures to counteract commercial pressures to enhance the prescribing of generics have seen considerably higher expenditures than those that have instigated a range of measures. Conclusions: There are considerable opportunities for European countries to enhance their prescribing efficiency, with countries already learning from each other. The 4E methodology allows European countries to concisely capture the range of current demand-side measures and plan for the future knowing that initiatives can be additive to further enhance their prescribing efficiency.

Keywords: drugs, generics, economics, pharmaceuticals, efficiency, sustainability 


\section{INTRODUCTION}

Scrutiny of pharmaceutical expenditures is increasing as this is the fastest growing cost component in ambulatory care, with pharmaceutical expenditures now typically the largest cost or equal largest component in this sector across Europe (Ess et al., 2003; Godman et al., 2008a; Simoens, 2008a; Coma et al., 2009; Barry et al., 2010; Sermet et al., 2010). Pharmaceutical expenditure is proportionally higher in middle and lower income countries at between 20 and $60 \%$ of total healthcare spending, although from a lower baseline (Cameron et al., 2009). The reasons for increasing expenditures are well known and include demographic changes, the continued launch of new expensive medicines, rising patient expectations and stricter clinical targets (Gumbs et al., 2007; Garattini et al., 2008; Lee and Emanuel, 2008; Barry et al., 2010). New biological drugs marketed at appreciably higher acquisition costs than previous standards provide additional impetus to this growth in expenditure enhancing the scrutiny (Caroll, 2005; Barrett et al., 2006; Lee and Emanuel, 2008).

This unsustainable growth has resulted in increasing urgency among governments, health authorities and health insurance companies to introduce reforms to improve prescribing efficiency for both new and existing drugs (Traulsen and Almarsdóttir, 2005; Toth, 2010). Supply side reforms for existing drugs include compulsory price cuts, measures to lower generic prices, reference pricing in a class (Anatomical Therapeutic Classification Level 4-World Health Organization [WHO], 2009) including voluntary reference pricing, as well as delisting products from the reimbursement list when they are considered no longer to be cost-effective versus current standards (Godman et al., 2008a,b, 2009a,b,c, 2010a; Simoens, 2008b; Teixeira and Vieira, 2008; Wettermark et al., 2008; Coma et al., 2009; Elshaug et al., 2009; McGinn et al., 2010; Sermet et al., 2010). Demand-side reforms and initiatives for existing drugs include measures to enhance the prescribing and dispensing of generics. This includes academic detailing and prescribing guidance incorporating electronic prescribing support systems, prescribing targets, financial incentives including incentives to enhance substitution in pharmacies, mandatory substitution unless prohibited by government agencies and administrative barriers to relegate the prescribing of patent protected products in a class or related classes to second line (Tilson et al., 2005; Gumbs et al., 2007; Hyde, 2007; Sakshaug et al., 2007; Sjöborg et al., 2007; Gouya et al., 2008; Simoens, 2008b,c; Godman et al., 2009a,c, 2010b; Wettermark et al., 2009a,b, 2010a; Krska and Godman, 2010; Martikainen et al., 2010; McGinn et al., 2010; Sermet et al., 2010). A number of these strategies are aimed at counter-acting the commercial activities of pharmaceutical companies, who have typically been the principal source of information among physicians for new drugs (Jones et al., 2001; Prosser et al., 2003; Szecseny, 2003; Watkins et al., 2003; Pegler and Underhill, 2005). This together with the complex nature of prescribing helps explain why pharmaceutical companies in the UK currently invest over $\mathfrak{\$} 850 \mathrm{mn}$ /year in marketing activities, with similar experiences across Europe (Beishon et al., 2007; Godman et al., 2008b).

Alongside this, governments, health authorities and health insurance agencies have instigated a range of measures to address physician and patient concerns with the effectiveness and/or side-effects of generics to release valuable resources. This urgency has increased with estimated global sales of products of \$US50 bn to \$US100 bn of products likely to lose their patents between 2008 and 2013 (Frank, 2007; Jack, 2008). The initiatives are similar and include defined criteria for granting substitutability status for generics, publishing lists of substitutable and non-substitutable products, not reimbursing generics where there are concerns with their quality, physician and patient education, encouraging International non-proprietary name (INN) prescribing as well as incentivizing pharmacists to talk with patients when substituting to allay any fears (Allenet and Barry, 2003; Valles et al., 2003; Kjoenniksen et al., 2006; Kopp and Vandevelde, 2006; Godman et al., 2008a, 2009a; Teixeira and Vieira, 2008; Versantvoort et al., 2008; Duerden and Hughes, 2010; Sermet et al., 2010). These concerns though generally only apply in a limited number of situations (Valles et al., 2003; Kjoenniksen et al., 2006; Heikkilä et al., 2007; Shrank et al., 2009). As a result, there should be considerable opportunities for European countries to further enhance their prescribing efficiency without compromising care. This should be welcomed as further reforms are essential to maintain comprehensive and equitable healthcare throughout Europe as we are already seeing European countries experiencing difficulties with funding new premium priced ambulatory care drugs even when these are considered cost-effective. Current activities to help fund new innovative drugs include (Cooke et al., 2005; DoH, 2006, 2008; Godman et al., 2009a; Krska and Godman, 2010; Wettermark et al., 2010b):

- placing them on "waiting lists" until more funding becomes available, e.g., Lithuania

- funding a limited number through special programs, e.g., "Therapeutic Programs" in Poland

- increasing planning activities to pro-actively address potential funding concerns. This includes ascertaining the potential role for new treatments ahead of launch as well as identifying potential areas to release resources, such as current treatments that well soon lose their patent, to fund new innovative treatments at launch, e.g., Sweden and UK. Subsequently monitoring prescribing of the new products against agreed guidance post launch

It is recognized it is difficult for countries to learn from each other in view of different circumstances and starting points, with one approach unlikely to fit all countries. In addition, prescribing behavior is complex (Grol and Grimshaw, 2003; Prosser et al., 2003; Prosser and Walley, 2005; Wettermark et al., 2009b). Having said this, there are examples of European countries learning from each other when considering new health reforms (Toth, 2010). In addition, the plethora of different measures introduced across Europe to enhance prescribing efficiency should stimulate debates within countries on additional reforms and initiatives that could be introduced. Coupled with this, cross national comparisons of drug utilization and expenditure also help identify possible additional reforms that countries could introduce through analytical studies linking datasets from different countries and regions and matching changes in utilization and expenditure with health policy initiatives.

The objectives of this paper are to assess the influence of the many supply and demand-side reforms and initiatives introduced across Europe to enhance prescribing efficiency in 
ambulatory care once a decision has been made to prescribe a particular class of drug. Subsequently utilize the findings to suggest potential future initiatives that countries could consider to further enhance their prescribing efficiency given continued resource pressures. This though acknowledging the complexities involved.

\section{MATERIALS AND METHODS}

This is a cross national retrospective observational study involving the analysis of reimbursed utilization and expenditure on a yearly basis for the Proton Pump Inhibitors (PPIs) and HMG CoA reductase inhibitors (statins) among European countries.

Nineteen European countries and regions took part in this study. These were Austria (AT), Croatia (HR), Estonia (EE), France (FR), Finland (FI), Germany (DE), Italy (IT), Lithuania (LT), Norway (NO), Portugal (PT), Poland (PO), Republic of Ireland (IE), Serbia (RS), Slovenia (SI), Spain (ES - only Catalonia), Sweden (SE), Turkey (TR), and the United Kingdom (GB-Eng - England and GB-Scot - Scotland). The countries reflect differences in geography, epidemiology, financing of healthcare, available resources for healthcare as well as different approaches to the pricing of generics, originators, and single sourced products (Table 1). They also reflect appreciable differences in the nature and extent of reforms and initiatives introduced to enhance the prescribing of generics. As a result, provide a number of exemplar initiatives and countries (Table A1 of Appendix).

The following definitions have been used to classify the different pricing approaches for generics across Europe, which build on previous publications (Godman et al., 2010a,c):

- Prescriptive pricing (PP) - mandated price reductions for generics for reimbursement compared with for instance prepatent loss prices for the molecule

- Market forces (MF) - no prescriptive pricing approaches; price reductions left to market forces with typically patients paying an additional co-payment for a more expensive product including branded generics than the current referenced priced molecule
- Mixed approaches (MA) - typically prescriptive pricing for the first generic or generics; market forces after that

We acknowledge though that in some countries only branded generics are available. However, to reduce confusion only the term "generics" will be used throughout the paper.

Only administrative databases were used to ensure standardization across countries. These included ( $100 \%$ coverage of the population unless stated):

- AT (Austria) - Data Warehouse of the Federation of Austrian Social Insurance Institutions (98\% of the population)

- DE (Germany) - GAMSI-Database, i.e., the GKV Arzneimittel Schnell-Information, which covers all prescriptions paid by the Social Health Insurance Funds (SHI - approximately 90\% of the population)

- EE (Estonia) - Estonian Health Insurance Fund

- ES (Spain - only Catalonia) - DMART (Catalan Health Service) database (all patients in Catalonia). Data only available from 2003 onwards

- FI (Finland) - Prescription Register of the Social Insurance Institution

- FR (France) - Medic'am database (CNAM-TS database for salaried personnel covering $75 \%$ of the population)

- GB - Eng (England) - Information Centre for Health and Social Care

- GB - Scot (Scotland) - Prescribing Information System (PIS) from NHS National Services Scotland Corporate Warehouse

- HR (Croatia) - Croatian Institute for Health Insurance

- IE (Republic of Ireland) - HSE-PCRS (GMS Population covering approximately $30 \%$ of the population with higher morbidity than the general population reflected in consuming approximately $65 \%$ of total pharmaceutical expenditure)

- IT (Italy) - OsMed database

- LT (Lithuania) - Electronic database of the National Health Insurance Fund

- NO (Norway) - Norwegian Prescription Database (NorPD). Expenditure data only available from 2004 onwards

Table 1 | Characteristics of the European countries in 2008 (using published definitions for generic pricing).

\begin{tabular}{|c|c|c|c|c|c|c|c|c|c|c|c|c|c|c|c|c|c|c|c|}
\hline & AT & DE & EE & ES & $\mathbf{F I}$ & FR & $\begin{array}{l}\text { GB - } \\
\text { Eng }\end{array}$ & $\begin{array}{l}\text { GB - } \\
\text { Scot }\end{array}$ & HR & IE & IT & LT & NO & PO & PT & RS & SE & SI & TR \\
\hline $\begin{array}{l}\text { Financing - } \\
\text { taxation }\end{array}$ & & & & $\checkmark$ & $\checkmark$ & & $\checkmark$ & $\checkmark$ & & $\checkmark$ & $\checkmark$ & & $\checkmark$ & & $\checkmark$ & & $\checkmark$ & & $\checkmark$ \\
\hline $\begin{array}{l}\text { Financing - } \\
\text { health insurance }\end{array}$ & $\checkmark$ & $\checkmark$ & $\checkmark$ & & & $\checkmark$ & & & $\checkmark$ & & & $\checkmark$ & & $\checkmark$ & & $\checkmark$ & & $\checkmark$ & \\
\hline Generics - MA & $\checkmark$ & & $\checkmark$ & $A C$ & $\checkmark$ & & & & $\checkmark$ & $\checkmark$ & $\checkmark$ & $\checkmark$ & & & $\checkmark$ & $\checkmark$ & & $\checkmark$ & \\
\hline $\begin{array}{l}\text { Reference } \\
\text { pricing - class } \\
\text { (ATC Level } 3 \text { or 4) }\end{array}$ & VP & $\checkmark$ & $\mathrm{NI}$ & $\mathrm{NI}$ & $A C$ & $\mathrm{NI}$ & RJT & RJT & $\checkmark$ & $\mathrm{NI}$ & $\checkmark$ & $A C$ & $\mathrm{NI}$ & $\checkmark$ & $\mathrm{NI}$ & Part & Only PPIs & $\mathrm{NI}$ & $\checkmark$ \\
\hline
\end{tabular}

Generic pricing: $A C$, actively considering. Reference pricing: VP, voluntary reference pricing; NI, not introduced; RJT, proposed but rejected; $A C$, active consideration; Part, partial applying to some product classes but not all. 
- PO (Poland) - National Health Fund database

- PT (Portugal) - INFARMED (NHS) database (approximately $75 \%$ of the population)

- RS (Serbia) - Republic of Serbia's Health Insurance Fund database

- SE (Sweden) - Apoteket AB (National Corporation of Swedish Pharmacies - monopoly up to 1 January 2010)

- SI (Slovenia) - The National Institute of Public Health and Health Insurance Institute Prescription Database

- TR (Turkey) - Social Security Institution (SGK) - single national public payer purchasing approximately $95 \%$ of pharmaceutical expenditure in Turkey

As discussed, two classes were chosen for in-depth analysis of ambulatory care prescribing efficiency. These were the PPIs Anatomical Therapeutic Chemical (ATC) A02BC, and the HMG CoA reductase inhibitors (statins) - ATC group C10AA (WHO, 2009). These two classes were chosen as (AFSSAPS, 2005; MeReC Extra, 2006; National Institute for Health and Clinical Excellence, 2006; Wessling and Lundin, 2006; Godman et al., 2008b, 2009a,b; Eriksson and Lundin, 2009; Martikainen et al., 2010; McGinn et al., 2010):

- they are both commonly prescribed in ambulatory care

- they also contain a mixture of generics, originators and single sourced products in a class and many patients, if not all in the case of PPIs, can be adequately managed with generic products

- PPIs and statins are typically the subject of country and/or regional initiatives to enhance prescribing efficiency
Utilization rates for the different molecules in each class were computed using Defined Daily Doses (DDDs), with utilization patterns in 2007 generally compared with 2001. These dates were chosen as typically both generic simvastatin and generic omeprazole became available and were reimbursed during this time period among Western European countries (Table 2). Simvastatin was the first major statin to become available as a generic in Europe with generally no or limited utilization of lovastatin. Omeprazole was the first PPI to become available as a generic. Both events resulted in demand-side initiatives to try and enhance the prescribing of generics ahead of more expensive patent protected products to improve prescribing efficiency (Table A1 of Appendix).

The concepts of ATC classification and DDDs were developed to facilitate cross country comparisons in drug utilization especially where there are differences in pack sizes and available tablet strengths (Bergman et al., 1979; Rønning et al., 2000; Rønning, 2002). DDDs are now internationally accepted for comparing drug utilization patterns across countries (Birkett, 2002; WHO, 2003; Walley et al., 2004a; Vlahović-Palcevski et al., 2010). The ATC index from 2010 was used in this study in line with WHO recommendations (Rønning et al., 2000).

Demand-side measures, i.e., initiatives and reforms to influence subsequent prescribing or dispensing of generics, have been collated under the " 4 Es," i.e., education, engineering, economics and enforcement. This approach has been used in other settings and successfully adapted to healthcare to provide a concise and easily understandable methodology to compare and contrast the complexity and multiplicity of demand-side measures implemented within and between countries (Coma et al., 2009; Godman et al., 2009a,c; Wettermark et al., 2009b; McGinn et al., 2010). Examples of the “4 Es" include:

Table 2 | Dates when generic omeprazole and generic simvastatin were first dispensed and reimbursed among European countries.

\begin{tabular}{|c|c|c|c|}
\hline Country & $\begin{array}{l}\text { Year when generic omeprazole } \\
\text { was dispensed and reimbursed }\end{array}$ & $\begin{array}{l}\text { Year when generic simvastatin } \\
\text { was dispensed and reimbursed }\end{array}$ & Comments \\
\hline AT (Austria) & 2003 & 2002 & \\
\hline EE (Estonia) & Before 2001 & 2001 & Reimbursement data only available from 2004 \\
\hline ES (Spain - Catalonia) & Before 2003 & Before 2003 & Data only available after 2003 \\
\hline GB - Eng (England) & 2002 & 2003 & \\
\hline GB - Scot (Scotland) & 2002 & 2003 & \\
\hline HR (Croatia) & Before 2000 & 2001 & Data will include 2000 to 2007 \\
\hline IE (Republic of Ireland) & 2002 & 2003 & \\
\hline IT (Italy) & 2007 & 2007 & $\begin{array}{l}2008 \text { compared with } 2006 \text { as both generic omeprazole } \\
\text { and generic simvastatin became available in } 2007\end{array}$ \\
\hline PT (Portugal) & Before 2001 & 2001 & \\
\hline RS (Serbia) & Before 2005 & Before 2005 & Data only available from 2005 onwards \\
\hline SE (Sweden) & 2003 & 2003 & \\
\hline SI (Slovenia) & Before 2001 & Before 2001 & \\
\hline TR (Turkey) & Before 2007 & Before 2007 & Data only available from 2007 to 2009 \\
\hline
\end{tabular}


- Educational activities - includes development and distribution of prescribing guidance right through to more intensive strategies such as educational outreach visits and benchmarking of physician prescribing habits

- Engineering activities - includes organizational or managerial interventions such as prescribing targets and compulsory INN prescribing as well as price: volume agreements for single sourced existing products

- Economic interventions - includes devolved budgets with penalties, positive and negative financial incentives, as well as differential patient co-payments for more expensive products than the current reference molecule

- Enforcement - includes regulations by law such as mandatory generic substitution and prescribing restrictions

Reimbursed expenditures from 2001 to 2007 were typically captured for each class to assess the influence of recent reforms on overall expenditure from a health authority or health insurance perspective. The only exceptions were Austria, Germany and Norway where there are difficulties with disassociating co-payments from total expenditure. However, this typically represents only a small proportion of overall expenditure in these three countries. Expenditure data was collected in local currency.

Reimbursed expenditures, as opposed to total expenditures, were chosen for the analysis as this is the actual expenditure incurred by health authorities or health insurance agencies reflecting the focus of the paper. Reimbursed expenditures in 2007 was subsequently converted to $€ / 1000$ inhabitants/year to compare expenditures across countries adjusted for population sizes. This includes currency conversions where pertinent to standardize the approach. This was based on established rates for the country; alternatively an average for the year from national banks (Godman and Wettermark, 2009a,b). 2007 was chosen for this calculation as this was the latest year for comprehensive data from all countries. Again, expenditure/1000 inhabitants/year is the internationally accepted standard approach for comparing expenditures across countries. Exchange rates used were $€ 1=0.734 \mathrm{~GB}$, LTL3.453, 8.219NOK, 3.783PLN, 79.24RSD and 9.25SEK (2007).

There has been no allowance for inflation in the analysis in order to directly compare the impact of different policies over time. In addition, health authorities and health insurance agencies typically refer to pre-patent loss prices when establishing reimbursed prices for generics especially for prescriptive pricing or mixed approaches to the pricing of generics (Godman et al., 2010a,c). It is acknowledged though that savings will be greater if inflation is factored in.

The data sets collected to compare prescribing efficiency for the PPIs and statins among the European countries included:

- Total DDDs 2001 and 2007

- DDDs/1000 inhabitants/day (DDDs/TID)

- Reimbursed expenditure in 2001 and 2007

- $€ / 1000$ inhabitants/year in 2007

- Principal reforms to lower the price of generics

- Principal demand-side reforms to enhance the prescribing of generic PPIs and statins compared with single sourced products collated under the $4 \mathrm{Es}$
Two principal analyses were undertaken for both the PPIs and statins to assess overall efficiency, with criteria subsequently broken down into three categories. These are summarized in Table 3. The three cut-off points for assessing efficiency were chosen intuitively; however, tested among the co-authors for internal validity.

In view of the limited number of peer-reviewed publications documenting current reforms for the pricing of generics, as well as current demand-side reforms and their impact especially for the PPIs and statins among the 19 European countries and regions outside of those from a number of the co-authors, details of these were typically provided by the co-authors. This method was also chosen to add robustness and standardization to the documentation since many of the co-authors are involved with either implementing or suggesting additional reforms in their country or region. This especially as there have been concerns with the accuracy of some of the health policy information contained within some of the web based publications (Blaszczyk et al., 2007).

No attempt has been made to analyze the appropriateness of prescribing of either the PPIs or statins. This is due to a lack of access to patient databases to determine the indication and/or doses prescribed. In addition, the main emphasis of this paper is regarding prescribing efficiency once a decision has been made by the physician to prescribe either a PPI or statin. These issues though have been discussed in individual country publications (Coma et al., 2009; Godman et al., 2009a,b,c; McGinn et al., 2010).

No impact analyses have been undertaken as typically multiple supply and demand-side initiatives were instigated in each country during the study period and the datasets generally covered the whole population. In addition, the intensity of different initiatives may vary over time and between different regions further hindering the usefulness of such analyses. This is reflected in the discussion. No regression lines have been added to Figures 3 and $\mathbf{4}$ as each point represents a different country subject to different supply and demand-side reforms (Table A1 of Appendix).

\section{RESULTS}

Table A1 in the appendix documents the main pricing reforms for generics during the study period among the 19 European countries and regions. Table A1 also documents the nature and intensity of the demand-side reforms introduced to enhance prescribing efficiency principally for the PPIs and statins collated under the " 4 Es." Any co-payments for the product and/or indication, in addition to the standard co-payment for the package, are also included in Table A1. This recognizes that some European countries use this "economic" approach to influence utilization.

Figure 1 demonstrated the influence of the various supply and demand-side measures (Table A1 of Appendix) on PPI prescribing efficiency among the different European countries and regions as measured by the rate of change in utilization (DDDs) versus reimbursed expenditure principally between 2001 and 2007. The countries have been broken down by:

- geography - into Central and Eastern European countries and the remainder, for the reasons discussed in Table 3

- the different approaches to pricing of generics - Prescriptive PP, Market Forces - MF, Mixed - MA 
Those showing considerable efficiency, in addition to general efficiency, i.e., below the line drawn, are highlighted using the definitions in Table 3.

In both Lithuania and Poland, there was approximately a twofold difference in the rate of increase in utilization (DDD basis) versus the rate of increase in reimbursed expenditure for the PPIs between 2001 and 2007, e.g., in Lithuania utilization increased 10.8-fold between 2001 and 2007 and Poland over 150-fold between 2002 and 2007. This appreciable increase in utilization following reimbursement, which was considerably greater than seen in the other European countries, led to their exclusion from Figure 1. Serbia was also excluded from Figure 1 with comprehensive data only recently becoming available, and after the availability of generic PPIs.
The various demand and supply side reforms instigated among the European countries and regions similarly influenced prescribing efficiency for the statins (Figure 2). The same categorization for efficiency has been used (Table 3), and again countries have been broken down into geography and approaches to the prescribing of generics.

In Poland, there was over a 140 -fold increase in statin utilization between 2002 and 2007 following their reimbursement, with overall a 4.5 -fold difference between the rate of increase in utilization versus the rate of increase in reimbursed expenditure between 2001 and 2007. This efficiency gain was helped by the instigation of reference pricing for the statins. Again, Serbia was excluded from Figure 2 with comprehensive data only recently becoming available.

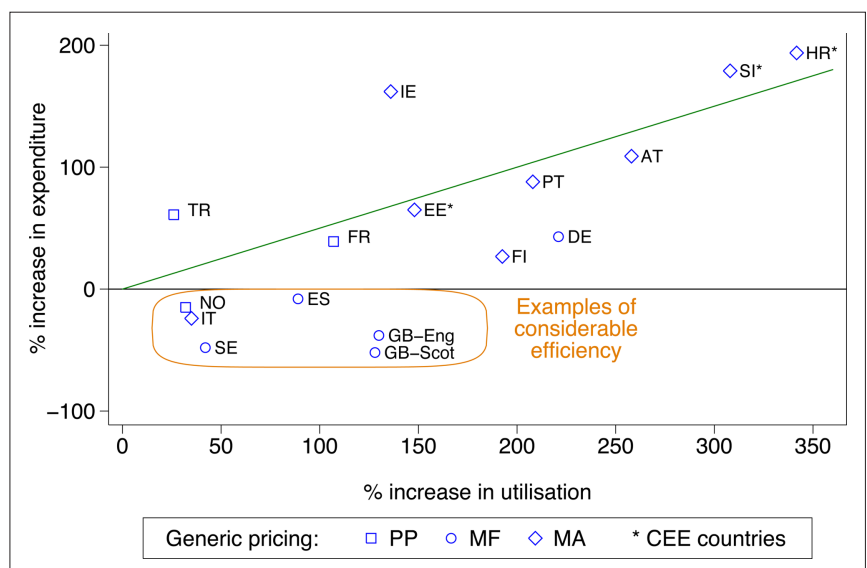

FIGURE 1 | Rate of increase in expenditure (local currency) versus the rate of increase in utilization (DDD based) for the PPIs principally from 2007 versus 2001 among European countries (unless stated), with generic pricing approaches divided into three categories. Standard EU country abbreviations have been used. ES = Catalonia (2007 versus 2003), $E E=2007$ versus 2004, HR $=2007$ versus 2000, IT = 2008 versus 2006 , $\mathrm{NO}=2007$ versus $2004, \mathrm{TR}=2009$ versus 2007

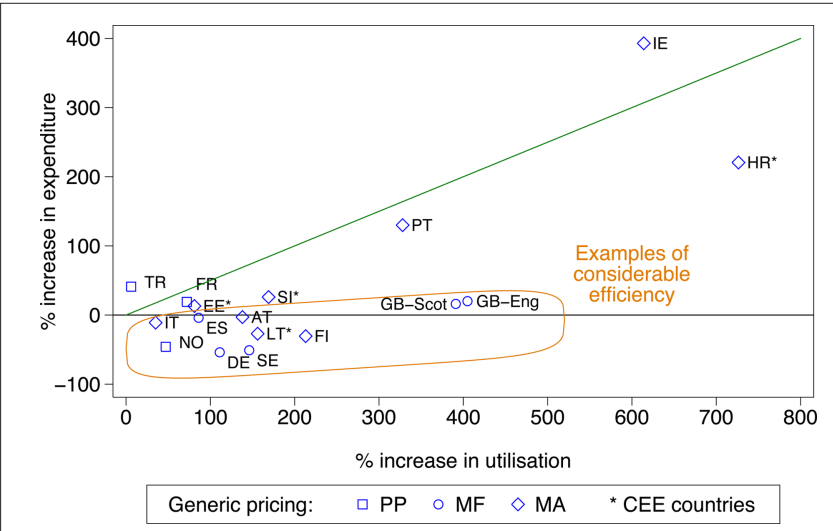

FIGURE 2 | Percentage change in utilization (DDDs) versus the percentage change in reimbursed expenditure (local currency) for the statins principally from $\mathbf{2 0 0 1}$ to 2007 among European countries. The countries again divided into former Central and Eastern European countries (CEE) with the approaches to generic pricing divided into three categories. Standard EU country abbreviations have been used. ES = Catalonia (2007 versus 2003), $\mathrm{EE}=2007$ versus 2004, $\mathrm{HR}=2007$ versus 2000, IT = 2008 versus 2006, $\mathrm{NO}=2007$ versus 2004, TR $=2009$ versus 2007 .

Table 3 | Principal measures used to evaluate changes in prescribing efficiency for both the PPIs and statins during the study years as well as categorize countries.

\begin{tabular}{lll}
\hline Objective $\quad$ Measure $\quad$ Efficiency criteria/comment
\end{tabular}

Assessment of overal prescribing efficiency

\author{
The increase in utilization rates \\ versus the increase in reimbursed \\ expenditure over time*
}

\footnotetext{
Three efficiency criteria

No efficiency - rate of increase in expenditure exceeds utilization Efficient countries - rate of increase in utilization more than double the rate of increase in expenditure Considerable efficiency - reimbursed expenditure decreasing over time despite increasing utilization. In the case of statins this also includes considerably increased utilization (over 350\% during the study period) with only a limited increase in expenditure (20\% or less)
}

\author{
Data treated with caution as different co-payment levels for \\ the PPIs and statins (Table $\mathbf{A} \mathbf{1}$ of Appendix) in addition to \\ any co-payment for the package \\ Extent of potential savings from \\ increasing prescribing efficiency \\ Overall utilization in 2007 (DDD/TID) compared \\ with overall expenditure (€/1000 inhabitants/year) \\ with both measures adjusted for population sizes
}

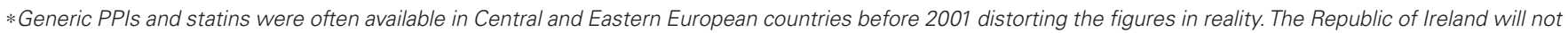

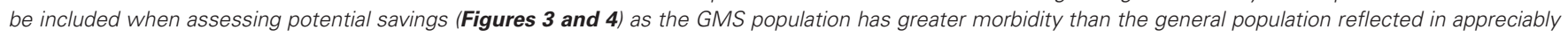
higher utilization of pharmaceuticals. 
The differences seen in prescribing efficiency for the PPIs (Figure 1) translate into considerable differences in overall expenditure adjusted for the differences in population sizes, i.e., expenditure expressed in $€ / 1000$ inhabitants/year and utilization by DDDs/1000 inhabitants/ day (DDD/TID) by 2007 (Figure 3). The differences in geography and approaches to the prescribing of generics have again been highlighted. Expenditure figures for the PPIs will be affected by whether there are high patient co-payment levels (Table Al of Appendix).

The differences seen in the rates of prescribing efficiency for the statins between 2001 and 2007 among European countries (Figure 2) are again reflected in considerable differences in overall expenditure in 2007 adjusted for population sizes (Figure 4). The differences in geography and approaches to the prescribing of generics have again been highlighted, with overall expenditures again affected by whether there are high co-payment levels for the statins (Table A1 of Appendix).

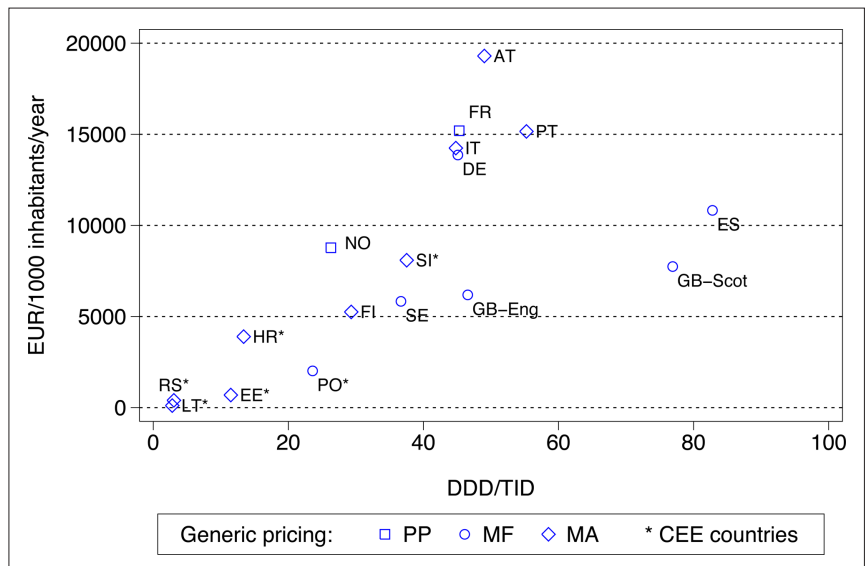

FIGURE 3 | Utilization (DDD/TID) and overall expenditure ( $€ / 1000$ inhabitants/year) for PPIs among European countries in 2007 (Italy 2008,

Serbia 2008). Standard EU country abbreviations have been used.

ES = Catalonia. Republic of Ireland not included as the GMS population has greater morbidity than the general population.

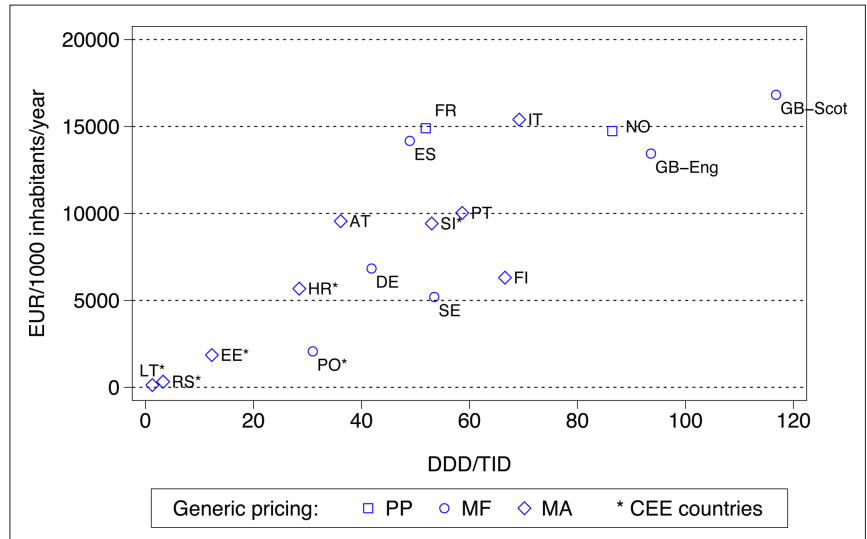

FIGURE 4 | Utilization (DDD/TID) and overall expenditure (€/1000 inhabitants/year) for the statins among European countries in 2007 (Italy 2008, Serbia 2008). Standard EU country abbreviations have been used. ES = Catalonia. Republic of Ireland not included as the GMS population has greater morbidity than the general population.

\section{DISCUSSION}

Additional reforms are essential across Europe to continue funding increased volumes and new drugs without prohibitive increases in either taxes or health insurance premiums. As such, we consider the findings from this study help provide future direction to health authorities and health insurance agencies as they seek to instigate additional measures. This is despite the limitations of the study design, which are discussed later.

General findings from the study include more limited utilization, and hence expenditure, of the PPIs and statins among Central and Eastern European countries compared with Western European countries (Figures 3 and 4). This is principally due to prescribing restrictions and higher patient co-payments in these countries (Table A1 of Appendix). This endorses the need to document ongoing reforms when comparing utilization rates across countries otherwise there could be concerns with the accuracy of the data provided. Table A1 of Appendix also demonstrates that the " 4 Es" provides a methodology for health authorities and health insurance agencies to comprehensively categorize their current demand-side initiatives ready for comparisons.

More specific findings include the fact that both supply and demand-side reforms are essential to maximize prescribing efficiency. The findings also demonstrate that the influence of the reforms appears to be additive, with "enforcement" having appreciable influence on subsequent utilization patterns.

Prescribing efficiency in Norway for the PPIs (Figure 1) is enhanced by its aggressive prescriptive pricing policy for generics, overcoming to some extent more limited demands side measures for the PPIs compared with Sweden and the UK (Table A1 of Appendix). The various pricing policies for generics in Austria, France and Portugal also helped improve prescribing efficiency with for instance the PPIs despite limited demand-side measures in these countries for this class (Table Al of Appendix). Overall though just concentrating on one aspect of reforms, i.e., either supply or demand-side measures but not both, will not help health authorities or health insurance agencies fully realize potential efficiency gains from the availability of generics. This is illustrated when comparing for instance prescribing efficiency for the statins in Sweden and the UK (England and Scotland) versus Germany (Figures 2 and 4). In Germany in 2007, there was very limited utilization of atorvastatin following the introduction of reference pricing for the class in 2003 at just $2 \%$ of overall statin utilization (Godman et al., 2009b) with rosuvastatin not available. This compares with 21 and $33 \%$ respectively on a DDD basis for the appreciably more expensive atorvastatin and rosuvastatin in Sweden and England in 2007 (Godman et al., 2010c). However, comparative expenditure appears similar or greater in Germany due to higher expenditure/DDD for simvastatin (Figure 4). There are also differences in prescribing efficiency between Croatia and Finland even though there are high patient co-payment levels in both countries. Prescribing efficiency has been enhanced in Finland by active reforms to lower generic prices, e.g., a 3-month's course of simvastatin during early 2006 was $€ 17$ versus $€ 127$ in 2002 before the introduction of generic substitution (Martikainen et al., 2010), as well as measures restricting the prescribing of atorvastatin and rosuvastatin (Table A1 of Appendix).

The additive nature of the demand-side measures is illustrated by greater prescribing efficiency in Catalonia (Spain), Sweden and the UK with their multiple and intensive measures based on education, 
engineering and economic initiatives (Table A1 of Appendix) compared with France, Portugal, the Republic of Ireland and Turkey (Figures 1 and 2) due generally to more limited demand-side measures in these countries (Table A1 of Appendix); although this is now changing in France (Sermet et al., 2010). These findings concerning the additive influence of demand-side measures endorse the results from previous studies which also showed that multiple interventions appear more successful in changing prescribing behavior than single interventions (Bero et al., 1998; Barton, 2001; Grol and Grimshaw, 2003; Prosser and Walley, 2005).

Introducing prior authorization, or other similar enforcement schemes, also enhances prescribing efficiency, e.g., statins in Austria, Germany and Norway (Figure 2), coupled with reforms to lower generic prices (Table A1 of Appendix). This compares with a more limited influence on prescribing efficiency for the PPIs in Austria with just "education" and "economic" measures in the absence of "enforcement" (Figure 1; Table A1 of Appendix). The improved efficiency seen with introducing "enforcement" measures for the statins in these three countries appears similar to the combination of extensive educational, engineering and economic initiatives for the statins in for instance England and Sweden (Figure 2; Table A1 of Appendix) along with measures to lower generic prices.

"Enforcement" can be also additive and introduced at any stage as seen in Austria where prescribing restrictions for atorvastatin built on existing educational and economic activities (Table A1 of Appendix; Godman et al.,2009c). This was also seen in Sweden where recent restrictions on Angiotensin Receptor Blockers have increased their prescribing second line building on existing educational, engineering, and economic initiatives among the counties (Wettermark et al., 2010a).

As a result of the differences in the nature and extent of demandside initiatives across these countries, there are appreciable differences in overall prescribing efficiency between France, Ireland and Portugal when compared with Catalonia (Spain), Sweden and the UK (Figures 1 and 2), and when adjusted for population sizes (Figures 3 and 4). Reimbursed expenditure is also high in Ireland in their selected GMS population at over $€ 60,000 / 1000$ inhabitants/ year for both the PPIs and statins.
There have been concerns that extensive demand-side measures including prescribing restrictions can alter the quality of subsequent care (Fein, 2010). However, a recent ecological study demonstrated similar surrogate outcomes in patients with hypercholesterolemia whether they were prescribed formulary drugs, i.e., generic simvastatin, or non-formulary drugs including atorvastatin (Norman et al., 2009). Recent studies conducted in the UK have also shown that patients can be successfully switched from atorvastatin to generic simvastatin without compromising care (Usher-Smith et al., 2008). Conserved resources can be re-directed to fund programs to improve compliance as well as fund increased volumes with the growing incidence of cardiovascular diseases. Compliance is a real concern in patients with chronic asymptomatic diseases (Cramer et al., 2008) rather than any minor differences in effectiveness between the statins in clinical trials, which is not seen in practice (Usher-Smith et al., 2008; Norman et al., 2009).

We are also seeing countries learning from each other as resources pressures grow. This builds on earlier examples generally within healthcare (Toth, 2010), with some examples contained in Table 4.

As discussed, we accept there are limitations with the study design, which are summarized in Table 5. However, some of these issues are less important when comparing changes in utilization and/or expenditure as opposed to comparing absolute numbers.

As a result, some of the findings especially regarding expenditures need to be treated with caution.

Never-the-less, we consider the findings will be of interest to health authorities and health insurance agencies as they plan future supply and demand-side measures to further improve their prescribing efficiency. We also believe the findings will be of interest to pharmaceutical companies as they plan for the future, especially as health authorities and health insurance agencies become increasingly proactive to conserve resources for existing products (Moon et al., 2010).

Ongoing initiatives to optimize the managed entry of new drugs will be discussed in future papers particularly as they underscore the notion that the funding of new premium priced products is an important challenge in Europe (Garattini et al., 2008).

Table 4 | Examples of countries learning from each other (Godman et al., 2008b, 2009a; Wettermark et al., 2008, 2010a; Barry et al., 2010; Martikainen et al., 2010; McGinn et al., 2010).

Measures

Supply side - pricing examples

Demand-side initiatives

\section{Examples}

Republic of Ireland introducing reference pricing for the molecule unless there are concerns such as a narrow therapeutic window

Health Insurance Fund in Lithuania actively considering reference pricing for the class

Republic of Serbia recently introducing policies to further lower the price of generics

The Office of Fair Trading in the UK proposing reference pricing for both the molecule and the class. The latter building on the recent experiences in Sweden with proposed reference pricing for the PPIs

Regions in Spain introducing prescribing targets linked with financial incentives Prescribing restrictions introduced for atorvastatin and rosuvastatin in Finland Compulsory INN prescribing in Lithuania unless prior approval granted

The national reimbursement agency in Sweden introducing prescribing restrictions for ARBs and patent protected statins to enhance prescribing efficiency compared with continuing with reference pricing (as seen with the PPIs - Table 1) as more complex disease areas than excess acid in the stomach Primary Care Trusts in the UK instigating therapeutic substitution and prior approval schemes to further enhance prescribing efficiency 
Table 5 | Limitations with the study design and rationale for some of the choices.

\section{Limitations}

No control groups in each country

Health authorities and health insurance agencies typically instigate multiple reforms over time; consequently, difficult to single out individual demand - side measures and their influence

No inclusion of OTC or hospital sales, which could impact especially on the findings for the PPIs where there are high patient co-payment levels Only administrative databases used and not compared with the findings from commercial sources such as Intercontinental Marketing Services (IMS) reflecting the focus of the paper. It is recognized there will be differences in utilization rates between IMS and administrative databases especially where there are high co-payments and/or appreciable restrictions on reimbursed population (seen in practice in Lithuania)

Prescribed daily doses (PDDs) were not used as no universal access to prescribing databases or IMS data across all countries. PDDs are likely to be a greater especially with the statins with higher doses advocated in recent guidelines (Walley et al., 2004b)

No universal access to patient databases also means no ability to link prescriptions with indications

Typically only reimbursed expenditure evaluated acknowledging total expenditure will be greater in countries with appreciable co-payments for statins and PPIs. This principally applies to France as well as Central and Eastern European countries (Table A1 of Appendix). In addition, reimbursed expenditures do not include any rebates or discounts given by generic manufacturers to community pharmacists to preferentially dispense their generic or the dispensing of parallel imported products at lower prices than current tariffs for the pack (the same though also applies to commercial databases). There are also variations in the extent of VAT added to dispensed packs across Europe. However, reimbursed expenditure was chosen to reflect the payer focus of the paper as well as provide standardization across countries

\section{ACKNOWLEDGMENTS}

We acknowledge the help of INFARMED with providing the NHS data for Portugal, Helga Festöy from NoMA with critique details of the pricing policy for generics in Norway, as well as the help of the NHS Information Centre in Leeds for the provision of the data

\section{REFERENCES}

Adamski, J., Godman, B., OfierskaSujkowska, G., Osinska, B., Herholz, H., Wendykowska, K., Laius, O., Jan, S., Sermet, C., Zara, C., Kalaba, M., Gustafsson, R., Garuoliene, K., Haycox, A., Garattini, S., and Gustafsson, L. L. (2010). Review of risk sharing schemes for pharmaceuticals: considerations, critical evaluation and recommendations for European payers. BMC Health Serv. Res.10, 153. doi: 10.1186/14726963-10-153

AFSSAPS. (2005). Prise en Charge Therapeutic du Patient Dyslipidemique. Available at: http://www.afssaps.fr/ var/afssaps_site/storage/original/ application/da2c055ce7845afe44d7aaca7c3f4de8.pdf [Accessed 20 July 2010].

Allenet, B., and Barry, H. (2003). Opinion and behaviour of pharmacists towards the substitution of branded drugs by generic drugs: survey of $1,000 \mathrm{com}$ munity pharmacists. Pharm. World Sci. 25, 197-202.

Barrett, A., Roques, T., Small, M., and Smith, R. (2006). How much will Herceptin really cost? BMJ 33, 1118-1120.

Barry, M., Usher, C., and Tilson, L. (2010). Public drug expenditure in the Republic of Ireland. Expert Rev. Pharmacoecon. Outcomes Res. 10, 239-245.
Barton, S. (2001). Using clinical evidence. BMJ 322, 503-504.

Beishon, J., McBride, T., and Scharaschkin, A. (2007). Prescribing Costs in Primary Care. National Audit Office. Available at: http://www. nao.org.uk/publications/0607/ prescribing_costs_in_primary_c. aspx?alreadysearchfor $=$ yes [Accessed 20 June 2010].

Bergman, U., Gimsson, A., Wahba, A., and Westerholm, B. (eds). (1979). Studies in Drug Utilization - Methods and Applications. Copenhagen: World Health Organization Regional Publications.

Bero, L., Grilli, R., Grimshaw, J., Harvey, E., Oxman, A., Tomson, M., On Behalf of the Cochrane Effective Practice and Organisation of Care Review Group. (1998). Getting research into practice. BMJ 317, 465-468.

Birkett, D. (2002). The future of ATC/ DDD and drug utilisation research. WHO Drug Inf. 16, 238-240.

Blaszczyk, P., Janiszewski, R., and Bondaryk, K. (2007).Poland-Pharma Profile; Pharmaceutical Pricing and Reimbursement Information. Available at: http://ppri.oebig.at/Downloads/ Results/Poland_PPRI_2007.pdf [Accessed 20 August 2010].

Cameron, A., Ewen, M., Ross-Degnan, D. Ball, D., and Laing, R. (2009). Medicine prices, availability and affordability

for England. We would also acknowledge the advice from Fredrik Granath at the Karolinska Institutet, Stockholm, Sweden regarding statistical analyses when typically multiple supply and demand-side measures are introduced during the study period. The study was in part supported by grants from the Karolinska Institutet.

in 36 developing and middle-income countries; a secondary analysis. Lancet 273, 240-249.

Caroll, J. (2005). Plans struggle for control of speciality pharma costs. Manag. Care 14, 41-48.

Coma,A., Zara, C., Godman, B.,Augusti,A. Diogene,E.,Wettermark, B., and Haycox, A. (2009). Policies to enhance the efficiency of prescribing in the Spanish Catalan Region: impact and future direction. Expert Rev. Pharmacoecon. Outcomes Res. 9, 569-581.

Cooke, J., Mason, A., Drummond, M., and Towse, A. (2005). Medication management in English national health service hospitals. Am. J. Health Syst. Pharm. 62, 189-195.

Cramer, J., Benedict, A., Muszabek, N. Keskinaslan, A., and Khan, Z. M (2008). The significance of compliance and persistence in the treatment of diabetes, hypertension and dyslipidaemia: a review. Int. J. Clin. Pract. 62, 76-87.

DoH. (2006). Good Practice Guidance on Managing the Introduction of New Healthcare Interventions and Links to NICE Technology Appraisal Guidance. Available at: www.dh.gov.uk/en/Publicationsandstatistics/Publications/ PublicationsPolicyAndGuidance/ DH_064983 [Accessed 20 July 2010].

DoH. (2008). How to Put NICE Guidance into Practice and Improve the Health and Wellbeing of Communities: Practical
Steps for Local Authorities. ISBN 1-84629-861-X. Available at: http:// www.nice.org.uk/media/163/5A/ HowputNICEguidancepracticelocal. pdf [Accessed 20 July 2010].

DoH. (2010). Better Care Better Value Indicator. Low Cost PPI Prescribing. Available at: http:// www.productivity.nhs.uk/Def IncreasingLowCostPPIPrescribing. aspx [Accessed 3 July 2010].

Duerden, M., and Hughes, D. (2010). Generic and therapeutic substitutions in the UK: are they a good thing? Br. J. Clin. Pharmacol. 70, 335-341.

Elshaug, A. G., Moss, J. R., Littlejohns, P., Karnon, J., Merlin, T. L., and Hiller, J. E. (2009). Identifying existing health care services that do not provide value for money. Med. J. Aust. 190, 269-273.

Eriksson, G., and Lundin, D. (2009). The Review of Medicines for Lipid Disorders. Available at: http://www.tlv.se/Upload/ Genomgangen/summary-lipids.pdf [Accessed 20 July 2010].

Ess, S., Schneeweiss, S., and Szucs, T. (2003). European healthcare policies for controlling drug expenditure. Pharmacoecnomics 21, 89-103.

Fattore, G., and Jommi, C. (2008). The last decade of Italian pharmaceutical policy - instability or consolidation? Pharmacoeconomics 26, 5-15.

Fein, O. (2010). Keep the single payer vision. Med. Care 48, 759-760. 
Festoy, H., Sveen, K., Yu, L.-M., Gjönnes, L., and Gregersen, T. (2008). Norway - Pharmaceutical Pricing and Reimbursement Information. Available at: http://ppri.oebig.at/Downloads/ Results/Norway_PPRI_2008.pdf [Accessed 3 August 2010].

Frank, R. (2007). The ongoing regulation of generic drugs. N. Engl. J. Med. 357, 1993-1996.

Garattini, S., Bertele, V., Godman, B., Wettermark, B., and Gustafsson, L. L. (2008). Enhancing the rational use of new medicines across European healthcare systems - a position paper. Eur. J. Clin. Pharmacol. 64, 1137-1138.

Godman, B., Bucsics, A., Burkhardt, T., Haycox, A., Seyfried, H., and Wieninger, P. (2008a). Insight into recent reforms and initiatives in Austria; implications for key stakeholders. Expert Rev. Pharmacoecon. Outcomes Res. 8, 357-371.

Godman, B., Haycox, A., Schwabe, U., Joppi, R., and Garattini, S. (2008b). Having your cake and eating it: Office of Fair Trading proposal for funding new drugs to benefit patients and innovative companies. Pharmacoeconomics 26, 91-98.

Godman, B., Shrank, W., Wettermark, B., Andersen, M., Bishop, I., Burkhardt, T., Garuoliene, K., Kalaba, M., Laius, O., Joppi, R., Sermet, C., Schwabe, U., Teixeira, I., Tulunay, F. C., Wendykowska, K., Zara, C., and Gustafsson, L. L. (2010a). Use of generics - a critical cost containment measure for all healthcare professionals in Europe? Pharmaceuticals 3, 2470-2494.

Godman, B., Bucsics, A., Burkhardt, T., Schmitzer, M., Wettermark, B., and Wieninger, P. (2010b). Initiatives to enhance renin-angiotensin prescribing efficiency in Austria: impact and implications for other countries Expert Rev. Pharmacoecon. Outcomes Res. 10, 199-207.

Godman, B., Shrank, W., Andersen, M., Berg, C., Bishop, I., T. Burkhardt, T., Garuoliene, K., Herholz, H., Joppi, R., Kalaba, M., Laius, O., McGinn, D., Samaluk, V., Sermet, C., Schwabe, U., Teixeira, I., Tilson, L., Tulunay, F. C., Vlahović-Palčevski, V., Wendykowska, K., Wettermark, B., Zara, C., and Gustafsson, L. L. (2010c). Comparing policies to enhance the utilisation generics across Europe: impact and global implications. Expert Rev. Pharmacoecon. Outcomes Res. 10, 707-722.

Godman, B., and Wettermark, B. (2009a). "Impact of reforms to enhance the quality and efficiency of statin prescribing across 20 European countries," in 9th Congress of the European
Association for Clinical Pharmacology and Therapeutics, Edinburgh, eds. D. Webb and S. Maxwell, Medimond International Proceedings Medimond s.t.l., Pianoro. ISBN 97888-7587-549-7, 65-69.

Godman, B., and Wettermark, B. (2009b). "Trends in consumption and expenditure of proton pump inhibitors (PPIs) in 20 European countries," in 9th Congress of the European Association for Clinical Pharmacology and Therapeutics, Edinburgh, eds D. Webb and S. Maxwell, Medimond International Proceedings Medimond s.t.l., Pianoro. ISBN 97888-7587-549-7, 71-75.

Godman, B., Wettermark, B., Hoffman, M., Andersson, K., Haycox, A., and Gustafsson, L.L. (2009a). Multifaceted national and regional drug reforms and initiatives in ambulatory care in Sweden; global relevance. Expert Rev. Pharmacoecon. Outcomes Res. 9, 65-83.

Godman, B., Schwabe, U., Selke, G., and Wettermark, B. (2009b). Update of recent reforms in Germany to enhance the quality and efficiency of prescribing of proton pump inhibitors and lipidlowering drugs. Pharmacoeconomics 27, 1-4.

Godman, B., Burkhardt, T., Bucsics, A., Wettermark, B., and Wieninger, P. (2009c). Impact of recent reforms in Austria on utilisation and expenditure of PPIs and lipid lowering drugs; implications for the future. Expert Rev. Pharmacoecon. Outcomes Res. 9, 475-484.

Gouya, G., Reichart, B., Bidner, A. Weissenfels, R., and Wolzt, M. (2008). Partial reimbursement of prescription chages for generic drugs reduces costs fr both healh insurance and patients. Wien. Klin. Wochenschr. 120, 89-95.

Grol, R., and Grimshaw, J. (2003). From best evidence to best practice: effective implementation of change in patients' care. Lancet 362, 1225-1230.

Gumbs, P., Verschuren, W., Souverein, P. Mantel-Teeuwisse, A. K., de Wit, G.A., de Boer, A., and Klungel, O.H. (2007). Society already achieves economic benefits from generic substitution but fails to do the same for therapeutic substitution. Br. J. Clin. Pharmacol. 64, 680-685.

Heikkilä, R., Mäntyselkä, P., HartikainenHerranen, K., and Ahonen, R. (2007). Customers' and physicians' opinions of experiences with generic substitution during the first year in Finland. Health Policy (New York) 82, 366-374.

Hyde, R. (2007). Doctors to pay for patients' medicine in Germany. Lancet 370,1118 .

Jack, A. (2008). Balancing Big Pharma's books. BMJ 336, 418-419.
Jones, I. M., Greenfield, S., and Bradley, P. (2001). Prescribing new drugs: qualitative study of influences on consultants and general practioners. BMJ 323 , 378-381.

Kjoenniksen, I., Lindbaek, M., and Grannas, A. (2006). Patients' attitudes towards and experiences of generic drug substitution in Norway. Pharm. World Sci. 28, 284-289.

Kopp, C., and Vandevelde, F. (2006) Use of international nonproprietary names (INN) among members. ISDB Newsl. 20, 2-4.

Krska, J., and Godman, B. (2010) Medicines Management in Pharmacy in Public Health, 2010. London: RPS Publishing (in press).

Lee, T., and Emanuel, E. (2008). Tier 4 drugs and the fraying of the social compact. N. Engl. J. Med. 359 , 333-335.

Magrini, N., Formoso, G., Marata, A., Capelli, O., Maestri, E., Voci, C. Nonino, F., Brunetti, M., Paltrinieri B., Maltoni, S., Magnano, L., Bonacini, M. I., Daya, L., and Viani, N. (2007). Randomised controlled trials for evaluating the prescribing impact of information meetings led by pharmacists and of new information formats in general practice in Italy. $B M C$ Health Services Research 7, 158. doi: 10.1186/1472-963-7-158

Martikainen, J., Saastamoinen, L., Korhonen, M., Enlund, H., and Helin-Salmivaara, A. (2010). Impact of restricted reimbursement on the use of statins in Finland. Med. Care 48, 761-766.

McGinn, D., Godman, B., Lonsdale, J., Way, R., Wettermark, B., and Haycox A. (2010). Initiatives to enhance the efficiency of statin and proton pump inhibitor prescribing in the UK; impact and implications. ExpertRev. Pharmacoecon. Outcomes Res. 10, 73-85.

MeReC Extra. (2006). NICE Appraise Statins. Available at: http://www.npc. co.uk/ebt/merec/cardio/cdlipids/ resources/merec_extra_no21.pdf [Accessed 20 July 2010].

Moon, J., Flett, A., Godman, B., Grosso, A., and Wierzbicki,A. (2010). Getting better value from the NHS drug budget. BMJ 341, c6449.

National Institute for Health and Clinical Excellence. (2006). Statins for the Prevention of Cardiovascular Events. Technology Appraisal 94 and Related Costing Template and Report. Available at: http://www.nice.org.uk/ [Accessed 20 July 2010].

Norman, C., Zarrinkoub, R., Hasselström, J., Godman, B., Granath, F., and Wettermark, B. (2009). Potential savings without compromising the quality of care. Int. J. Clin. Pract. 63 , 1320-1326.
Office of Fair Trading (UK). (2007). The Pharmaceutical Price Regulation System: An OFT Study. Annexe A: MarketforPrescription Pharmaceuticals in the NHS. London: The Office of Fair Trading [online]. Available at: http:// www.oft.gov.uk/shared_oft/reports/ comp_policy/oft885a.pdf [Accessed 3 July 2010].

Pegler, C., and Underhill, J. (2005). Evaluating promotional material from industry: an evidence-based approach. Pharm. J. 274, 271-274.

Peura, S., Rajaniemi, S., and Kurkijärvi, U. (2007). Pharmaceutical Pricing and Reimbursement Information Finland. Available at: http://ppri. oebig.at/Downloads/Results/Finland_ PPRI_2007.pdf [Accessed 2 August 2010].

Prosser, H., Almond, S., and Walley, T. (2003). Influences on GPs' decision to prescribe new drugs-the importance of who says what. Fam. Pract. 20, 61-68.

Prosser, H., and Walley, T. (2005). A qualitative study of GPs' and PCO stakeholders' views on the importance and influence of cost on prescribing. Soc. Sci. Med. 60, 1335-1346.

Rønning, M. (2002). A historical overview of ATC/DDD methodology. WHO Drug Inf. 16, 233-234.

Rønning, M., Blix, H. S., Harbø, B. T., and Strøm,H. (2000). Different versions of the anatomical therapeutic chemical classification system and the defined daily dose - are drug utilisation data comparable? Eur. J. Clin. Pharmacol. 56, 723-727.

Sakshaug, S., Furu, K., Karslstad, Ø., Rønning, M., and Skurtveit, S. (2007). Switching statins in Norway after new reimbursement policy - a nationwide prescription study. Br. J. Clin. Pharmacol. 64, 476-481.

Schmacke, N., and Lauterberg, J. (2002). Criticism of new German chronic disease management is unfair. $B M J$ 325, 971.

Sermet, C., Andrieu, V., Godman, B., Van Ganse, E., Haycox, A., and Reynier, J. P. (2010). Ongoing pharmaceutical reforms in France; considerations for other countries and implications for key stakeholder groups in France. Appl. Health Econ. Health Policy 8, 7-24

Shrank, W., Cox, E., Fischer, M., Mehta, J., and Choudhry, N. K. (2009). Patients' perception of generic medications. Health Affairs 28, 546-556.

Simoens, S. (2008a). Developing competitive and sustainable Polish generic medicines market. Croat. Med. J. 50, 440-448.

Simoens, S. (2008b). Generic medicine pricing in Europe: current issues and future perspective. J. Med. Econ. 11, $171-175$. 
Simoens, S. (2008c). Trends in generic prescribing and dispensing in Europe. Exp. Rev. Clin. Pharmacol. 1, 497-503.

Sjöborg, B., Bäckstrom, T.,Arvidsson, L.-B., Andersén-Karlsson, E., Blomberg, L. B., Eiermann, B., Eliasson, M., Henriksson, K., Jacobsson, L., Jacobsson, U., Julander, M., Kaiser, P. O., Landberg, C., Larsson, J., Molin, B., and Gustafsson, L. L. (2007). Design and implementation of a point-of-care computerised system for drug therapy in Stockholm metropolitan health region - bridging the gap between knowledge and practice. Int. J. Med. Inform. 76, 497-506.

Stock, S., Schmit, H., Buscher, G., Gerber, A., Drabik, A., Graf, C., Lüngen, M., and Stollenwerk, B. (2010). Financial incentives in the German Statutory Health Insurance: new findings, new questions. Health Policy 96, 51-56.

Szecseny, J. (2003). Influence of attitudes and behaviour of GPs on prescribing costs. Qual. Saf. Health Care 12, 6-7.

Teixeira, I., and Vieira, I. (2008). Pharmaceutical Pricing and Reimbursement Information Portugal. Available at: http://ppri.oebig.at/ Downloads/Results/Portugal_ PPRI_2008.pdf [Accessed 2 August 2010].

Tilson, L., Bennett, K., and Barry, M. (2005). The potential impact of implementing a system of generic substitution on the community drug schemes in Ireland. Eur. J. Health Econ. 50, 267-273.

Toth, F. (2010). Healthcare policies over the last 20 years: reforms and counterreforms. Health Policy (New York) 95, 82-89.

Traulsen, J., and Almarsdóttir, A. (2005). The argument for pharmaceutical policy. Pharm. World Sci. 27, 7-12.

Usher-Smith, J., Ramsbottom, T., Pearmain, H., and Kirby, M. (2008). Evaluation of the clinical outcomes of switching patients from atorvastatin to simvastatin and losartan to candesartan in a primary care setting: 2 years on. Int. J. Clin. Pract. 62, 480-484.

Valles, J.-A., Barreiro, M., Cereza,G., Ferro, J. J., Martínez, M. J., Escribà, J. M.,
Iglesias, B., Cucurull, E., and Barceló, E. (2003). A prospective multicentre study of the effect of patient education on acceptability of generic prescribing in general practice. Health Policy 65, 269-275.

Versantvoort, C., Maliepaard, M., and Lekkerkerker, F. (2008). Generics: what is the role of authorities. Neth. J. Med. 66, 62-66.

Vlahović-Palčevski, V., Gantumur, M., Radoševic, N., Palčevski, G., and Vander Stichele, R. (2010). Coping with changes in the defined daily dose in a longitudinal drug consumption database. Pharm. World Sci. 32 125-129.

Von Ferber, L., Bausch, J., Koster, I. Schubert, I., and Ihle, P. (1999). Pharmacotherapeutic circles. Pharmacoeconomics 16, 273-283.

Walley, T., Folino-Gallo, P., Schwabe, U. and Van Ganse, E. (2004a). Variations and increase in use of statins across Europe: data from administrative databases. BMJ 328, 385-386.

Walley, T., Folino-Gallo, P., Schwabe, U., Van Ganse, E., Stephens, P. and EuroMedStat Group. (2004b). Comparison of national administrative and commercial databases to monitor expenditure and costs of statins across. Europe. Eur. J. Clin. Pharmacol. 60, 503-511.

Watkins, C., Harvey, I., Carthy, P., Moore, L., Robinson, E., and Brawn, R. (2003). Attitudes and behaviour of general practioners and their prescribing costs: a national cross sectional survey. Qual. Saf. Health Care 12, 29-34.

Wessling, A., and Lundin, D. (2006). The Review of Drugs Against Disease Caused by Acid Stomach-A Summary. Solna: Pharmaceuticals Benefits Board [online]. Available at: http://www.tlv. se/Upload/Genomgangen/summarystomach-acid.pdf [Accessed 5 July 2010].

Wettermark, B., Godman, B., Andersson, K., Gustafsson, L. L., Haycox, A. and Bertele' V. (2008). Recent national and regional drug reforms in Sweden - implications for pharmaceutical companies in Europe. Pharmacoeconomics 26, 537-550.

Wettermark, B., Godman, B., Neovius, M. Mellgren, T.O., and Kahan, T. (2010a). Initial effects of a reimbursement restriction to improve the cost-effectiveness of antihypertensive treatment. Health Policy 94, 221-229.

Wettermark, B., Persson, M. E., Wilking, N., Kalin, M., Korkmaz, S., Hjemdahl, P., Godman, B., Petzold, M., and Gustafsson, L. L. for the Regional Drug Expert Consortium. (2010b). Forecasting drug utilization and expenditure in a metropolitan health region. BMC Health Services Research 10:128. doi: 10.1186/1472-6963-10-128

Wettermark, B., Pehrsson, A., JuhaszHaverinen, M., Veg, A., Edlert, M. Törnwall-Bergendahl, G., Almkvist, H., Godman, B., Granath, F., and Bergman, U. (2009a). Financial incentives linked to self-assessment of prescribing patterns - a new approach for quality improvement of drug prescribing in primary care. Qual. Prim. Care $17,179-189$.

Wettermark, B., Godman, B., Jacobsson, B., and Haaijer-Ruskamp, F. (2009b) Soft regulations in pharmaceutical policymaking - an overview of current approaches and their consequences. Appl. Health Econ. Health Policy 7 , $1-11$.

World Health Organization. (2003). Introduction to Drug Utilisation Research. WHO International Working Group for Drug Statistics Methodology, WHO Collaborating Centrefor Drug Statistics Methodology, WHO Collaborating Centre for Drug Utilization Research and Clinical Pharmacological Services. Available at: http://www.who.int/medicines/ areas/quality_safety/safety_efficacy/ Drug\%20utilization\%20research.pdf [Accessed 20 July 2010].

World Health Organization. (2009). Guidelines for ATC Classification and DDD Assignment 2009. Oslo: WHO Collaborating Centre for Drug Statistics Methodology.Available at: www.whocc. no [Accessed 20 July 2010].
Conflict of Interest Statement: The majority of the authors are employed directly by health authorities or health insurance agencies or are advisers to these organizations. No author has any other relevant affiliation or financial involvement with any organization or entity with a financial interest in or financial conflict with the subject matter or materials discussed in the manuscript, although Morten Andersen has received teaching grants from the Danish Association of Pharmaceutical Industries for providing education on pharmacoepidemiology. No writing assistance was utilized in the production of this manuscript.

Received: 24 September 2010; paper pending published: 22 October 2010; accepted: 30 November 2010; published online: 07 January 2011.

Citation: Godman B, Shrank W, Andersen $M$, Berg C, Bishop I, Burkhardt T, Garuoliene K, Herholz H, Joppi R, Kalaba $M$, Laius $O$, Lonsdale J, Malmström RE, Martikainen JE, Samaluk V, Sermet C, Schwabe U, Teixeira I, Tilson L, Tulunay FC, Vlahović-Palčevski V, Wendykowska $K$, Wettermark B, Zara $C$ and Gustafsson LL (2011) Policies to enhance prescribing efficiency in Europe: findings and future implications. Front. Pharmacol. 1:141. doi: 10.3389/fphar.2010.00141

This article was submitted to Frontiers in Pharmaceutical Medicine and Outcomes Research, a specialty of Frontiers in Pharmacology.

Copyright (c) 2011 Godman, Shrank, Andersen, Berg, Bishop, Burkhardt Garuoliene, Herholz, Joppi, Kalaba, Laius, Lonsdale, Malmström, Martikainen, Samaluk, Sermet, Schwabe, Teixeira, Tilson, Tulunay, Vlahović-Palčevski, Wendykowska, Wettermark, Zara and Gustafsson. This is an open-access article subject to an exclusive license agreement between the authors and the Frontiers Research Foundation, which permits unrestricted use, distribution, and reproduction in any medium, provided the original authors and source are credited. 


\section{APPENDIX}

Table A1 | Pricing approaches for generics and major demand-side measures principally for the PPIs and statins among the different European countries typically up to 2007 (Von Ferber et al., 1999; Schmacke and Lauterberg, 2002; Wessling and Lundin, 2006; Hyde, 2007; Magrini et al., 2007; Office of Fair Trading, 2007; Peura et al., 2007; Sakshaug et al., 2007; Fattore and Jommi, 2008; Festoy et al., 2008; Godman et al., 2008a,b, 2009b,c, 2010a,b,c; Simoens, 2008a; Teixeira and Vieira, 2008; Wettermark et al., 2008, 2009a,b, 2010a; Eriksson and Lundin, 2009; Adamski et al., 2010; Barry et al., 2010; DoH, 2010; Martikainen et al., 2010; McGinn et al., 2010; Sermet et al., 2010; Stock et al., 2010).

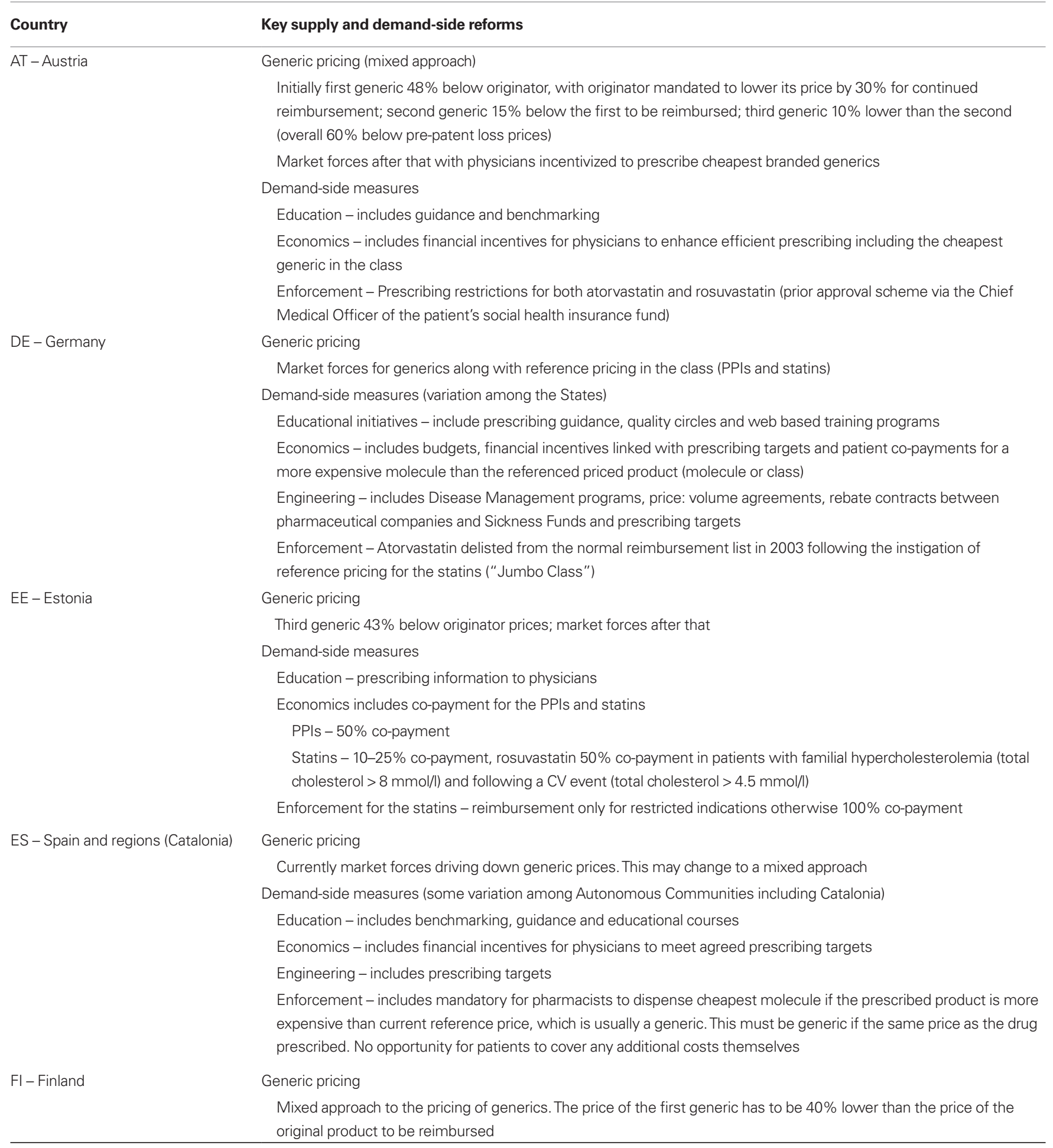


Table A1 | (continued)

\section{Country}

FR - France

GB - England

GB - Scotland

$H R-($ Croatia)

\section{Key supply and demand-side reforms}

Prices of subsequent generics must not be higher than the first generic to be reimbursed with market forces driving down prices with the introduction of generic substitution with the cheapest product from 2003. Substitution mandatory unless forbidden by the physician or patient; although there can be higher co-payments for more expensive products

Demand-side measures

Education - clinical guidelines as well as EBM initiatives to enhance the quality of prescribing. However, no prescribing targets as seen in a number of other European countries

Economics - principally via patient co-payments

2001: PPIs - €8.41/purchase plus 50\% co-payment (Basic Refund Category), similarly for statins for most patients. Patients with familial hypercholesterolemia or coronary artery disease entitled to lower co-payment at €4.20/ purchase and $25 \%$ co-payment

2007: PPIs 58\% co-payment; similarly for the statins unless familial hypercholesterolemia or coronary artery disease entitlement where only $28 \%$ co-payment (applied to $15 \%$ of statin users)

Enforcement - in 2006 atorvastatin and rosuvastatin restricted to second line as appreciably more expensive than other statins with limited additional benefit (restriction for atorvastatin subsequently abolished in 2009 with the availability of generic atorvastatin and reference pricing for the molecule)

Generic pricing

Prescriptive pricing for generics with the first generic priced $55 \%$ below the originator for reimbursement. Prices further reduced by $7 \%$ after 18 months.

Demand-side measures

Education - includes campaigns to enhance the prescribing and dispensing of generics through for instance benchmarking of physician prescribing and campaigns to allay fears regarding generics

Economics

Incentives to physicians, patients and pharmacists to enhance the prescribing and dispensing of generics versus originators including encouraging physicians to prescribe by INN name

Co-payments - working out on average $20 \%$ for PPIs and statins (when factoring in patients with long term illness)

Engineering

Price: volume agreements for existing compounds)

Campaigns from 2009 to enhance the prescribing of generics in a class through prescribing targets linked with financial incentives (CAPI - Contrats d'amélioration des pratiques individuelles) prescribing targets (engineering)

Generic pricing

Market forces with transparency in pricing of generics coupled with high INN prescribing. This has typically resulted in low prices for generics

Demand-side measures (national and local with some variation among Primary Care Trusts)

Education - includes for instance national and local prescribing guidance (e.g., NICE, British National Formulary and PCT prescribing guidance), benchmarking and academic detailing

Economics - budget devolution, Practice Based Commissioning and physician financial incentives

Engineering - includes Better Care, Better Value indicators for low cost PPIs and statins as well as prescribing support programs encouraging active therapeutic substitution. In addition, proactively managing the introduction of new generics through encouraging the prescribing of patent protected products in a class that will soon lose their patent ahead of other single sourced products in a class

As for England

However, budgets not devolved locally (GPs responsible for their drug budgets but not accountable)

Generic pricing

Mixed approach. The first generic should not be priced higher than $70 \%$ of the originator pre-patent price to be reimbursed (originator price dropping by at least $10 \%$ )

Second generic - a maximum of $90 \%$ of the price of the first generic for reimbursement; third generic maximum price of $90 \%$ of the second with market forces further lowering prices with patients paying the difference for a more expensive molecule than the current reference 
Table A1 | (continued)

\section{Country}

IE - Republic of Ireland

IT - Italy

LT - Lithuania

NO - Norway

\section{Key supply and demand-side reforms}

Demand-side measures

Education - National formulary providing prescribing guidance, with only a limited number of treatment guidelines Engineering includes - price: volume agreements - although applies to new drugs

Economics includes higher co-payments for more expensive products that the reference molecule. It also includes co-payments for the statins and PPIs

For the statins - in 2003 - 25\% co-payment for secondary prevention in patients with ischemic heart disease or cerebrovascular disease and with patients with diabetes with aTC > $5 \mathrm{mmol} / / ; 75 \%$ for patients for primary prevention whose 10 -year chance of $\mathrm{CHD}>20 \%$ or will be at the age of 60 . Reimbursement only if treatment initiated for patients $<70$ years

In 2006, similar to 2003 for secondary prevention (25\%). Primary prevention includes TC > 7 mmol/l after 3 months $\operatorname{diet}(75 \%$ co-payment).

In 2008 (outside study period), no co-payment for patients meeting criteria for primary and secondary prevention - co-payment only if they wish originator atorvastatin

For the PPIs - typically no co-payment in patients where $\mathrm{H}_{2}$ blockers no longer working for esophageal reflux, alternatively for Zollinger Elisonov syndrome or eradication of Helicobacter pylori; otherwise $100 \%$ co-payment

Enforcement - Access to patient history to check criteria for reimbursement, e.g., statins and PPIs

Generic pricing

Overall mixed approach with the recent introduction of a two step price reduction process for patent expired products - 20\% reduction on patent expiry (in 2007) followed by a further 15\% reduction after 22 months (in 2011) (expected to realise $€ 275 \mathrm{mn}$ by 2011)

Demand-side measures

Limited demand-side reforms to date to encourage the prescribing of generic drugs first line

Generic pricing

The first generic $20 \%$ below the originator; market forces after that

Demand-side measures (Variation among health authorities)

Educational initiatives - guidelines, academic detailing and benchmarking

Economics - financial incentives for GPs, additional patient co-payment for more expensive molecules than the reference molecule

Engineering - capping ambulatory care budgets

Enforcement - prescribing restrictions for certain indications

Generic pricing

Currently first generic $30 \%$ below originator, second and third generics $10 \%$ below this; market forces after that

Demand-side measures

Education - some guidelines in place to encourage rational use of medicines but not obligatory. In addition auditing of prescribing habits with possible financial penalties for excessive costs

Economics - includes co-payments for PPIs and statins, as well as possible financial penalties for physicians (above)

PPIs $-50 \%+$ for majority of indications

Statins - Only 20\% co-payment. Initially statins only reimbursed for secondary prevention (post event) and for only 6 months. Reimbursement restrictions now lifted for generic statins

Engineering - includes obligatory INN prescribing unless concerns ( compulsory from 2010 unless prior authorization from Hospital or Polyclinic Therapeutic Committee)

Enforcement (statins only) - reimbursement only post AMI and only for 6 months (reimbursement restrictions now lifted for generic statins). In addition, the first prescription must be written by a cardiologist otherwise $100 \%$

co-payment

Generic pricing

Aggressive prescriptive pricing policy for generics with high volume generics $85 \%$ below originator prices

Demand-side measures

Limited educational initiatives during the study period 
Table A1 | (continued)

\section{Country}

Country

PO - Poland

PT - Portugal

RS - Serbia

\section{Key supply and demand-side reforms}

\section{Enforcement}

PPIs - prescribing of esomeprazole restricted in 2007. Specialists though required to verify the diagnosis and recommend therapy

Statins - atorvastatin restricted from 2005 (rosuvastatin not reimbursed) with physicians encouraged to actively substitute patients currently prescribed atorvastatin. Spot checks undertaken amongst physicians if abuse suspected

Generic pricing

Market forces driving down generic prices. In addition reference pricing in a class and across therapeutic groups (ATC Levels 3 and 4)

Demand-side measures

Education - generally limited educational interventions; although variable among the regions

Economics - includes co-payment for the indication as well as additional co-payment for a more expensive brand than the reference product (molecule, class, or therapeutic area)

PPIs - 30\% (apart from esomeprazole which is not reimbursed)

Statins $-30 \%$ (apart from rosuvastatin which is not reimbursed)

Enforcement - Pharmacists are obliged to inform patients about generic products if they have the same active ingredient, dosage, package and route of administration as the prescribed product but cheaper (as branded generics in Poland)

Generic pricing

Mixed approach to the pricing of generics with the first generic priced at least $35 \%$ below the originator; this reduces to $20 \%$ if the originator price is below $€ 10 /$ pack. Further price reductions in 2005, 2007, and 2008

2005 and $2007-6 \%$ price reduction for all reimbursed medicines

After March 2007 also annual price reductions for generics depending on the market share of each active substance $(5,9$, or $12 \%)$

2008 - further $30 \%$ price reduction for generic medicines

2010 - further changes to try and reduce prices within homogeneous groups, i.e., same active substance, pharmaceutical form, strength and route of administration

In addition, ongoing activities by pharmaceutical companies to suspend market authorization for generics as a counter measure. The official database from Infarmed (July 2010) includes 17 active substances and more than 500 medicines (packages) where marketing authorization has been suspended

Demand-side measures

Education - includes guidelines (although not mandatory) and campaigns promoting generics. The latter include patient campaigns via TV, radio, leaflets in hospitals and community pharmacies as well as physicians updated every quarter by INFARMED of available generics

Economics - includes establishing a Reference Price System (RPS) in 2002 defining a fixed amount paid by the NHS for homogeneous groups. In May 2010 no co-payment for pensioners (100\% reimbursement) whose income is below the national minimum wage (the so called Special Regime). In June 2010, new legislation reimbursing 100\% only the five cheapest medicines in a homogeneous group

Engineering - Agreements between the Portuguese Pharmaceutical Industry (represented by APIFARMA) and the Ministry of Health with the objective of limiting the growth in the NHS expenditure on pharmaceuticals

Enforcement - includes since 2002 an obligation for physicians to prescribe by INN for medicines with approved generics; however they can prohibit substitution where patient concerns. Pharmacists are allowed to substitute generics where physicians have prescribed by INN name and have not prohibited substitution, and should also inform patients about generic prices versus originators (however no financial incentives for this)

Generic Pricing

Mixed approach with the first generic priced at least a minimum of $80 \%$ of average current prices in three reference countries (Slovenia, Croatia and Italy)

Subsequent generics should be priced similar or lower to gain market share with the lowest price product establishing the reference price for the molecule

In addition, to help further lower prices originator and generic drugs must now have the same price for reimbursement with no opportunity for patients to pay an additional co-payment for a more expensive product 


\section{Table A1 | (continued)}

\section{Country}

SE - Sweden

SI - Slovenia

TR - Turkey

\section{Key supply and demand-side reforms}

Demand-side measures

Economics - Patients initially required to pay an additional co-pay for a more expensive product than the current reference price (same INN name - ATC Level 5) - now changing (above). Prescribing efficiency helped by early availability of generics - similar to the situation in Poland (above)

Enforcement - Prior authorization schemes in place for selected premium priced drugs based on step therapy approaches

Generic pricing

Market forces driving down prices with compulsory generic substitution

Demand-side measures (some variation among the Counties)

Education - includes a range of measures incorporating prescribing guidance and guidelines, routine benchmarking against colleagues and against recommended drugs, as well as electronic prescribing support systems

Economics - includes devolved budgets and financial incentives

Engineering - includes prescribing targets such as \% of statins as generic statins

Enforcement - includes prescribing restrictions for rosuvastatin (since launch) and atorvastatin (post 2007)

Generic pricing

First generic no higher than an average of $82 \%$ of prices in Austria, France and Germany; market forces after that

Demand-side measures

Education - includes the Health Insurance Institute organizing therapeutic meetings and undertaking audits of prescribing habits

Economics - includes additional co-payments for more expensive compounds than the reference product

Enforcement - includes prescribing restrictions for certain drugs based on their more limited value versus current standards

Generic pricing

The first generic must be priced no higher than $66 \%$ of the originator's pre-patent loss price; subsequently subject to

a $11 \%$ price reduction

Demand-side measures

Education - limited activities to date

Enforcement - some prescribing restrictions but not applying to PPIs or statins 